\title{
BARRIERS FOR EMPOWERMENT IN ORGANISATIONS ON THE BASIS OF SURVEYS
}

\author{
Anna KUŁAKOWSKA*, Zdzisław PIĄTKOWSKI**, Wojciech ŻEBROWSKI*** \\ *,**University of Ecology and Management in Warsaw, 02-061 Warszawa, Poland \\ *e-mail: ann1960@wp.pl; **ulises@onet.eu \\ ***Faculty of Management, Department of Production Management \\ Warsaw University of Technology, 02-524 Warszawa, Poland \\ e-mail: w.zebrowski@wz.pw.edu.pl
}

\begin{abstract}
The objective of the paper is to present the results of investigation regarding barriers for empowerment in the context of organisational problems of companies, their application in the search for solutions, and adequate implementation in order to increase the efficiency of the processes of decision-making.
\end{abstract}

Key words: organization, organizational structure, manager, personnel, superior, empowerment, delegating power.

\section{Introduction}

One of the concepts of personnel management in organisations which lead to strength and independence of employees is empowerment - which is particularly controversial among practitioners and theoreticians of management. The notion of empowerment is often reduced to a simple delegation of power, and it is this kind of simplifications which imply numerous misunderstandings and objections to the effect that this is an "old formula in a new disguise " [4, p. 684-695].

Empowerment is nevertheless a far more complex and multidimensional idea - it comprises virtually all the aspects of functioning of an organisation. It links the organisational level (organisational empowerment) with the psychological, individual plane of each employee, and this is precisely what implies its power [5, p. 1]. The organisational empowerment may be construed as a body of deliberate managerial actions and practices, which give the subordinates power, control and authority. The purpose of those actions is empowering of employees - namely their strength and independence through an organisational context which gives rise to the state of empowerment, i.e. empowerment at the individual and psychological plane. The psychological empowerment is perception of being empowered. R.M. Kanter, who defines the organisational empowerment as delegating of power to employees, considers a continuum of power - from absolute powerlessness to the state of being empowered [2, p. 358-370].

Since the modern capitalism is a recent phenomenon in our country, it seems important to present the situation of the Polish companies and their properties which are relevant from the point of view of implementation of empowerment. This is precisely the subject of the paper.

\section{Scope of investigation}

The subject of the analysis are the results of the surveys realised in June 2009 in state and private companies of different sizes in the province of Mazowsze. The analysis was realised in 50 randomly selected companies. 500 questionnaires were handed out, and 218 of them were filled out and returned. The questionnaire was anonymous and realised without participation of third parties.

The presented data are a part of a wider project which includes more specific and detailed problems. This paper presents a concise summary of the most important properties of the companies in Mazowsze and their employees, as regards the perspective of implementation of empowerment. The other results and conclusion implied by the study, which relate to more specific issues will be published in two other papers.

\section{$3 \quad$ Analysis and interpretation of empirical studies}

Analyzing the obtained data regarding the level of education of respondents, it may be noted that the most numerous groups are those with post-secondary and secondary education. The former includes 63 people $(29,1 \%$ of all the respondents), while the latter includes 50 people $(23,1 \%$ of all the respondents). The group with an M.A. includes 46 people $(21,3 \%$ of all the respondents), while the group with a B.A. or an en- 
gineering degree includes 39 people $(18,1 \%$ of all the respondents). Among all the respondents may also be distinguished a group of those who have a postgraduate studies and solely vocational studies. Among all the respondents there were 14 people $(6,5 \%$ of all the respondents) with post-graduate studies and solely 4 people $(1,9 \%$ of all the respondents) with vocational education.

While evaluating the level of education of the aforementioned groups of respondents, it must be noted that most managers and middle-level directors have an engineering degree (Table 1). 5 managers have an engineering degree (25\% of all the managers) as well as 9 middle-level directors $(37,5 \%$ of all the directors in this group). Most commonly the low-level managers have post-secondary education (6 directors, which means $50 \%$ of this group of respondents), while independent specialists have an M.A. degree (12 independent specialists, which means $41,4 \%$ of this group of respondents).

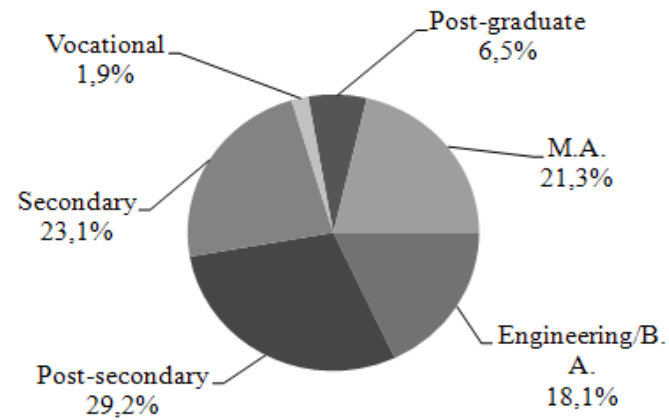

Figure 1. Level of education of the respondents (source: [3])

Most commonly specialists have post-secondary education (12 of them, which means $30 \%$ of this group of respondents), line employees have a secondary education (6 of them, which means $25 \%$ of this group of respondents), and assistants have a post-secondary education ( 5 of them, which means $41,7 \%$ of this group of respondents).

It must be emphasized that only 3 managers have a post-graduate education $(15 \%$ of this group of respondents), which is the case of two middle-level directors $(8,3 \%$ of this group of directors $)$ and 5 independent specialists $(17,3 \%$ of this group of specialists). Such a high level of education is also the case for one specialist $(2,5 \%$ of this group of respondents) and one line employee $(6,3 \%$ of this group of respondents).

The data obtained in regard to the functions the respondents have in the companies where they are employed indicate that the majority were specialists and senior specialists. Specialists formed a group of 40 people $(18,5 \%$ of all the respondents), while independent specialists formed a group of 29 people $(13,4 \%$ of all the respondents). What is important is that the study included also middle- and low-level directors and managers. The former group of those respondents was formed by 24 people $(11,1 \%$ of all the respondents). The group of managers was slightly less numerous and it included 20 people $(9,3 \%$ of all the respondents), while the group of low-level directors included 12 respondents (5,6\% of all the respondents). Among the respondents there were also line employees and assistants. The former group included 16 people ( $7,4 \%$ of all the respondents), while the latter included 12 people $(5,6 \%$ of all the respondents). Apart from the aforementioned groups of respondents, there was another group of respondents specified as ,others”.

Table 1. Level of education for specific groups of respondents

(source: [3])

\begin{tabular}{|c|c|c|c|c|c|c|}
\hline \multirow[b]{2}{*}{ Position } & \multicolumn{6}{|c|}{ Education } \\
\hline & Post-graduate & M.A. & $\begin{array}{l}\text { Engineer- } \\
\text { ing/B.A. }\end{array}$ & $\begin{array}{c}\text { Post- } \\
\text { secondary }\end{array}$ & Secondary & $\begin{array}{c}\text { Vocation- } \\
\text { al }\end{array}$ \\
\hline manager & 3 & 4 & 5 & 3 & 5 & \\
\hline middle-level director & 2 & 4 & 9 & 5 & 4 & \\
\hline low-level director & & 1 & 1 & 6 & 4 & \\
\hline independent specialist & 5 & 12 & 7 & 2 & 3 & \\
\hline specialist & 1 & 9 & 7 & 12 & 11 & \\
\hline line employee & 1 & 2 & 2 & 4 & 6 & 1 \\
\hline assistant & & & 2 & 5 & 4 & 1 \\
\hline others & 2 & 14 & 6 & 26 & 13 & 2 \\
\hline
\end{tabular}


This most numerous group which included 63 people $(29,2 \%$ of all the respondents) was formed by respondents employed at positions which are different to those specified above. Since this group included people employed at various positions, which require distinct qualifications, and who have different levels of education (e.g. human resources clerk, security personnel and caretaker), in spite of a relatively elevated number of people in this group, the discussion omit the indications of this group of respondents.

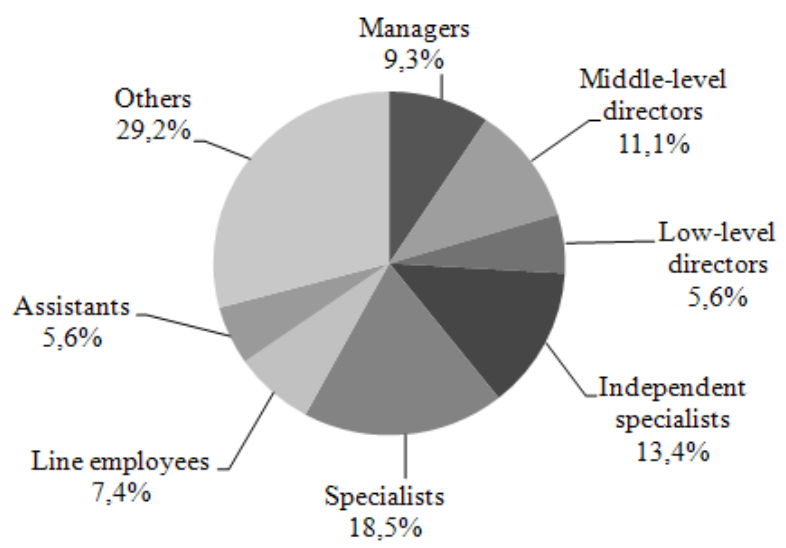

Figure 2. Positions occupied by the respondents (source: [3])

Analyzing the relevant data regarding the seniority of the respondents, it may be noted that the seniority of $1 / 3$ of the respondents is shorter than two years, and the seniority of a similar group exceeds ten years. The seniority of slightly more than $20 \%$ of the respondents amounts to 2-5 years, and the seniority of the remaining $15 \%$ is $6-10$ years.

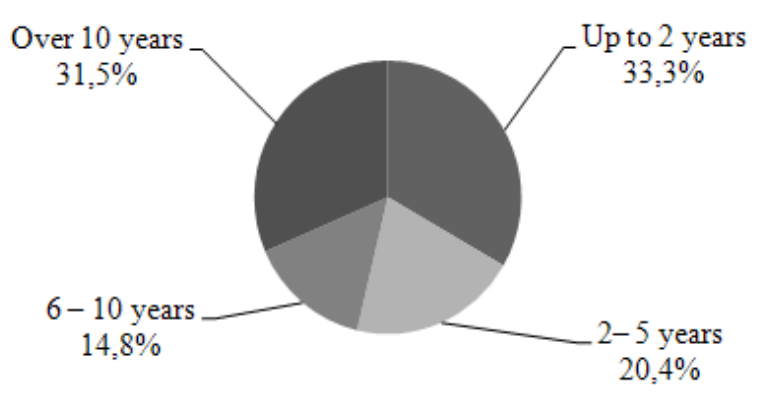

Figure 3. Seniority of the respondents (source: [3])

What is interesting is the data regarding seniority in relation to the positions of the groups of respondents.

The data presented in Table 2 indicate that the seniority of managers and directors is relatively long. The seniority of $70 \%$ of the total number of managers amounts to at least six years, while six among the managers ( $30 \%$ of this group of respondents) have been on their positions for more than ten years. The seniority of as many as 14 middle-level directors $(58,4 \%$ of this group of respondents) and eight low-level directors exceeds 10 years. The situation in both the groups of specialists is different, since the seniority of the majority of them does not exceed five years. Furthermore, 17 independent specialists $(58,6 \%$ of this group of respondents) and 22 specialists (55\% of this group of respondents) have been on their positions for not more than five years. In case of line employees, the seniority of six among them $37,5 \%$ of this group of respondents) exceeds ten years, while over $66 \%$ assistants have been on their positions for not more than two years.

Table 2. Seniority of specific groups of respondents

(source: [3])

\begin{tabular}{|l|c|c|c|c|}
\hline \multicolumn{1}{|c|}{ Position } & up to 2 years & $2-5$ years & $6-10$ years & over 10 years \\
\hline manager & 1 & 5 & 8 & 6 \\
\hline middle-level director & 1 & 6 & 3 & 14 \\
\hline low-level director & & 2 & 2 & 6 \\
\hline independent specialist & 9 & 8 & 6 & 13 \\
\hline specialist & 14 & 8 & 5 & 6 \\
\hline line employee & 4 & 5 & 1 & 3 \\
\hline assistant & 8 & 1 & & 12 \\
\hline others & 36 & 8 & 7 & 6 \\
\hline
\end{tabular}




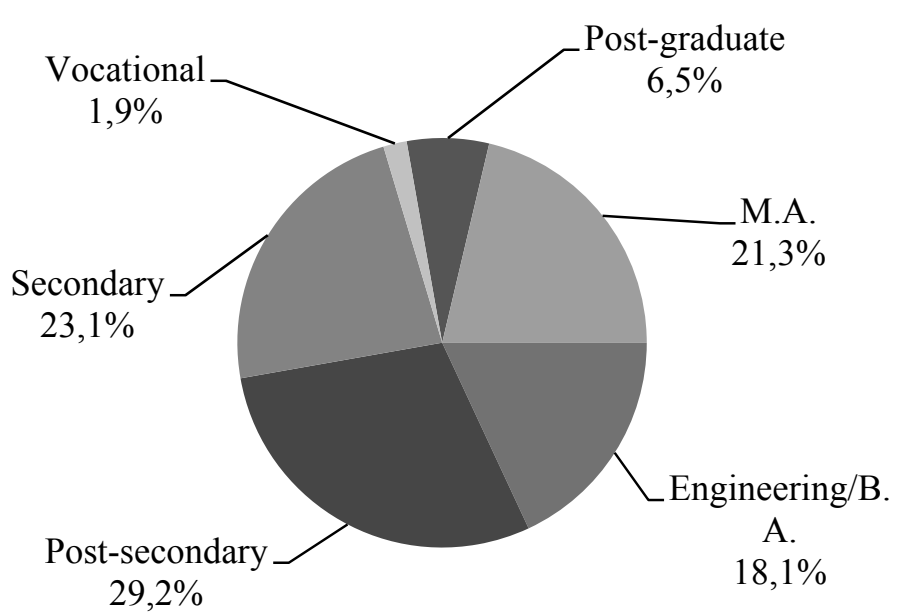

Figure 4. Properties of the respondents' companies (source: [3])

Having classified the respondents regarding the form of ownership of their companies, as well as the number of employees in those companies, it was determined that the most numerous group of respondents amounting to 60 people ( $27,8 \%$ of all the respondents) is employed in state companies which employ at least 151 employees. Slightly fewer, namely 47 respondents ( $21,8 \%$ of all the respondents) are employed in private companies which also employ at least 151 employees. The fewest respondents work in state companies which employ 51-150 people.

It must be also noted that most managers, i.e. eight of them ( $40 \%$ of this group of respondents) are employed in the smallest private companies, which employ between 3 and 50 employees. Most directors are employed in state companies which employ more than 150 employees, since in such companies are employed as many as nine middle-level directors $(45 \%$ of this group of respondents) and seven low-level directors $(58,3 \%$ of this group of respondents). In the same group of companies there are most respondents who are employed at a position of specialist and independent specialist. In case of specialists, there are as many as 20 people $(50 \%$ of this group of respondents), while in case of independent specialists the group amounts to eight people $(27,6 \%)$. It must be emphasized that the same percentage of respondents who are employed as independent specialists work in private companies which employ more than 150 employees.

Analyzing the structure of employment of respondents employed as assistants and line employees, it may be noted that most assistants, i.e. three of them $(25 \%$ of this group of respondents) work in state companies which employ between 51 and 150 employees, and the same number in private companies which employ more than 150 employees, while most, namely eight line employees (50\% of this group of respondents) work in state companies which employ more than 150 employees. The aforementioned distribution of employment indicates that the conclusions from the analysis of indications of the respondents may not reflect adequately the analysed aspects of empowerment in state companies which employ up to 50 employees.

Coming to a conclusion of the analysis of the studied population, we must draw attention to the education of the respondents in relation to the ,properties” of their companies, since assuming that during selection of respondents their education was not an important factor, the distribution of education in accordance with the form of ownership and the size of the companies, taking into account the percentage of the respondents employed in the specified groups of companies, permits to determine general tendencies in the employment policy in these groups of companies. 
Table 3. Number of respondents employed in companies of distinct forms of ownership and size, in accordance with their education (source: [3])

\begin{tabular}{|c|c|c|c|c|c|c|c|}
\hline \multirow{2}{*}{ Education } & \multirow{2}{*}{ Total } & \multicolumn{3}{|c|}{$\begin{array}{c}\text { State company } \\
\text { Number of employees }\end{array}$} & \multicolumn{3}{|c|}{$\begin{array}{l}\text { Private company } \\
\text { Number of employees }\end{array}$} \\
\hline & & $3-50$ & $51-150$ & $>150$ & $3-50$ & $51-150$ & $>150$ \\
\hline post-graduate & 14 & 4 & 2 & 6 & 1 & 1 & \\
\hline M.A. & 46 & 9 & 3 & 16 & 4 & 3 & 11 \\
\hline engineering & 39 & 3 & 5 & 9 & 9 & 8 & 5 \\
\hline post-secondary & 63 & 4 & 3 & 13 & 16 & 7 & 20 \\
\hline secondary & 50 & 7 & 6 & 14 & 7 & 5 & 11 \\
\hline vocational & 4 & & & 2 & 2 & & \\
\hline \multicolumn{8}{|l|}{ others } \\
\hline \multicolumn{8}{|c|}{ state companies } \\
\hline $3-50$ employees & 27 & 27 & & & & & \\
\hline $51-150$ employees & 19 & & 19 & & & & \\
\hline >150 employees & 60 & & & 60 & & & \\
\hline \multicolumn{8}{|c|}{ private companies } \\
\hline 3 - 50 employees & 39 & & & & 39 & & \\
\hline $51-150$ employees & 24 & & & & & 24 & \\
\hline$>150$ employees & 47 & & & & & & 47 \\
\hline
\end{tabular}

Analysing the data in Table 3, it may be noted that as many as 12 people with post-graduate education (85,7\% in this group of respondents) and 28 people with an M.A. (60,9\% of this group of respondents) are employed in state companies of different sizes, although those companies employ only $49,1 \%$ of all the respondents. Such disproportions in the proclivity to people post-graduate education or an M.A. in state and private companies (the rate is at least 6:4) may constitute a basis for the hypothesis that the intention of private companies, in opposition to state companies, is primarily to employ people with a specific specialization, who in extreme cases are „human automata" for the employers. The high probability of this thesis may be illustrated by the fact that as many as 43 respondents with a post-secondary education (68,3\% of all the respondents) are employed in private companies, in which work $50,1 \%$ of all the respondents. The aforementioned statements are also confirmed by the requirements for candidates and the policy of recruitment for new plants, as was the case in the Opel plant in Gliwice.

Analysing the responses given by the respondents regarding specific actions and attitudes, which are characteristic for the respondent's superior, if they delegate a part of their authority. The respondents might indicate that the superior: tightens the control and supervision, reduces the control and supervision, rewards commitment and initiative, facilitates access to information, questions skills and qualifications of the employees, and demonstrates a lack of confidence towards the employees.

The respondents gave altogether 338 responses; since 217 responses related to version 2-4, and solely 121 responses related to version 1 as well as 5 and 6, it may justify a thesis that the respondents believe the attitudes of their superiors once they have delegated power to the subordinates are more often correct than not (the relation is $217: 121$ ).

Altogether $39,4 \%$ of all the respondents indicated that the superior, once he has delegated power to the subordinate, increases the control and supervision of such a person, while solely $16,2 \%$ of the respondents indicated that the superiors in such situations do precisely the opposite, namely limit the control and supervision.

A significant part of the respondents, namely as many as $43,9 \%$, indicated that after delegation of power the superior rewards commitment and initiative of the subordinates, and $40,3 \%$ of the respondents indicated that in such situations superiors provide a better access to information for the subordinates. A relatively small group, namely $7,4 \%$ of the respondents indicated that 
in such situations the superior questions the skills and qualifications of the employees, and 9,3\% indicated that the superior demonstrates a lack of confidence towards the employees.

Analysing the distribution of responses given by the respondents (from the groups of respondents specified in relation to their positions) regarding control and supervision exercised by the superiors after delegation of power to the subordinates, it may be noted that the respondents in all the groups more often indicate that the superiors in such situations increase supervision and control of the subordinates rather than reduce them. The highest percentage of the people who indicate an increase of supervision is in the group of assistants $(58,3 \%)$ and managers, middle- and low-level directors (50\% each), and the lowest in the group of specialists $(25 \%)$. The highest percentage of the people who indicate a decrease of control in such situations is in the group of low-level directors $(33,3 \%)$ and managers $(30 \%)$, while the lowest is in the group of line employees $(6,3 \%)$.

As regards the level of those percentage values, it might be said that generally the higher position occupied by the respondents, the higher the percentage of those who indicate that after delegation of power, the superior limits supervision and control.

Analysing the responses given by the respondents regarding (taking into account their education), it may be said that they believe that after delegation of power, the superiors rather increase than limit the control. The highest percentage of the people who indicate an increase of supervision is in the group with an engineering education $(46,1 \%)$, post-secondary education $(44,4 \%)$ and post-graduate education $(42,8 \%)$, and the lowest in the group of people with an M.A. (30,4\%). The highest percentage of the people who indicate a decrease of control in such situations is in the group of people with an M.A. (30,4\%), while the lowest is in the group of people with an engineering education $(7,7 \%)$.

It must be also emphasized that the longer the seniority, the lower the percentage of the respondents who say that the superiors intensify the control (from $43 \%$ in the group of respondents whose seniority is shorter than two years to $36,8 \%$ in the group of respondents whose seniority is longer than ten years). The responses also indicate that the longer the seniority, the higher the percentage of those who believe that the superiors reduce control (from $11,1 \%$ in the group of the respondents whose seniority is shorter than two years to $20,6 \%$ in the group of the respondents whose seniority is longer than ten years). Coming to a conclusion of the analysis of responses regarding control, it must also be indicated that who indicated an increase of control in such situations were the respondents employed in private companies. Do the managers of such company believe that ,the master's eye makes the horse fat"? The reason for a relatively low number of responses indicating intensification of supervision and control of people employed in state companies is probably the fact that the directors in such companies do not care much about their job.

As regards the 95 responses $(43,9 \%$ of all the respondents) related to the superiors rewarding commitment and initiative in a situation of delegation of power, it must be emphasized that the superiors of the other group of respondents $(56,1 \%$ of all the respondents) probably do not perceive or do not want to perceive the motivational function of rewarding. Without dwelling however upon the subject of motivation and its absence, it should be noted that the highest percentage of people who claim that their superiors in the indicated situations reward commitment and initiative is in the group of managers $(55 \%)$ and assistants $(50 \%)$, and the lowest in the group of line employees $(37,5 \%)$ and low-level directors (25\%). The highest percentage of the respondents, who claim that such rewarding takes place, is in the group of people with an M.A. (50\%), and the lowest in the group of people with a post-graduate education.

However who indicates such rewarding of the employees most commonly are the respondents whose seniority amounts to $6-10$ years $(62,5 \%$ of the total number of people in this group of respondents), and where such a response is least common is among those whose seniority is the longest $(32,4 \%$ of the total number of people in this group of respondents), but there is no evident correlation between the seniority and the frequency of such responses. It should also be emphasized that such rewarding is more frequently indicated by the respondents working in companies which employ up to 50 employees. 


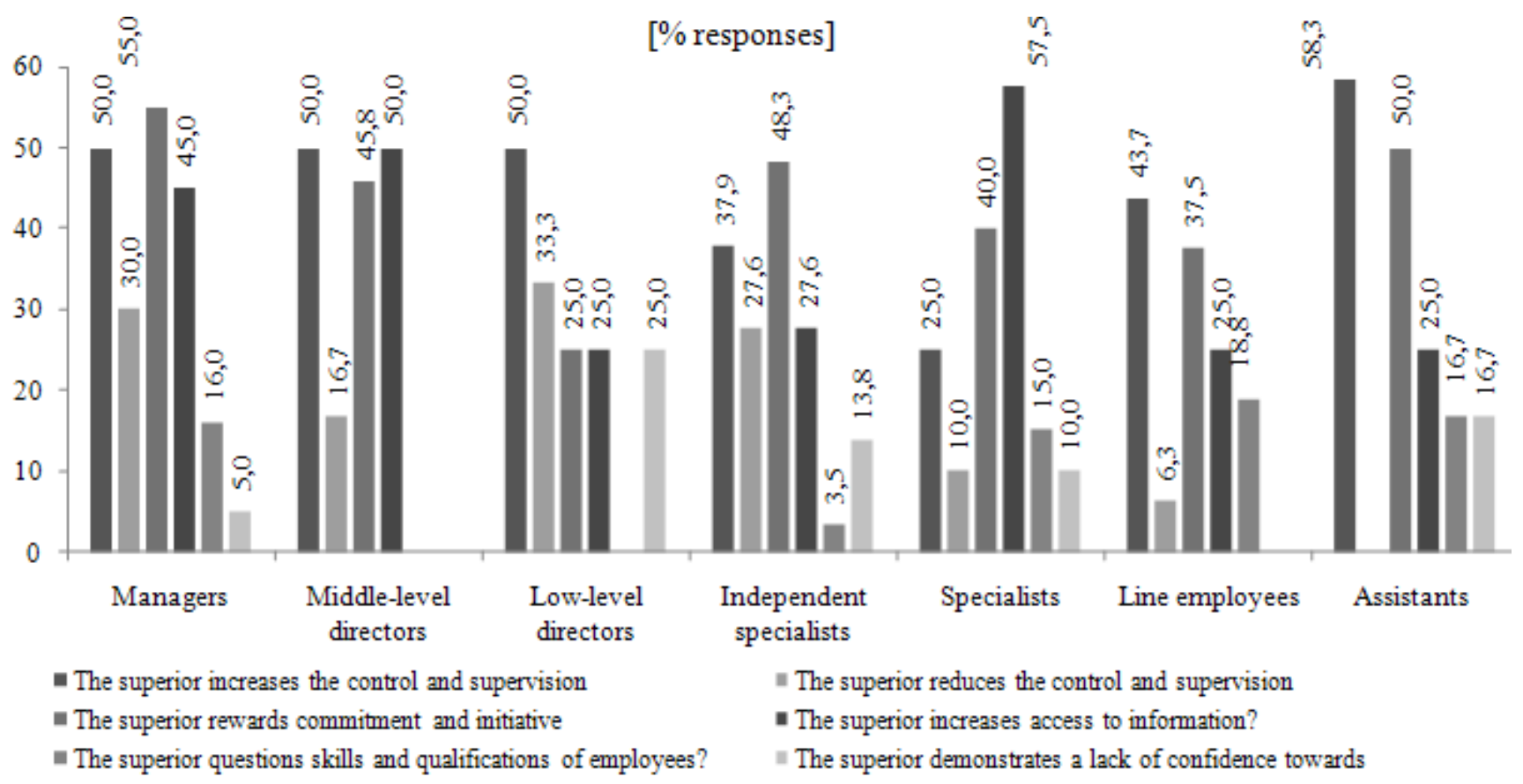

Figure 5. Respondents' responses to the question which among the specified actions and attitudes are characteristic for their superior, if he delegates a part of his authority

(source: [3])

Taking into account the 87 responses $(40,3 \%$ of all the respondents) regarding an increasing access to information after delegation of power, it must be emphasized that almost $60 \%$ of the respondents' superiors do not consider the fact that apart from the crucial information in the decision-making process, the access to the information which might not be indispensable within the given scope of responsibilities has also a major motivational importance. The highest percentage of the respondents who indicated that in the specified situations their superiors increase the access to information is in the group of specialists $(57,5 \%)$ and middle-level directors (50\%), while the lowest is among the low-level directors, line employees and assistants (25\% each). The distribution of the percentage of responses in accordance with the education is approximately equal (from 36\% to $46 \%$ ), except for the employees with a post-graduate education $(21,4 \%)$, who probably before had a wide access to different kinds of information regarding the company.

Relatively infrequently the respondents responded that after delegation of power the superiors demonstrate doubts about skills and qualifications of the employees (16 responses $-7,4 \%$ of all the respondents), as well as a lack of confidence towards the employees (20 responses $-9,3 \%$ of all the respondents). Taking into account the number of responses indicating a higher level of control, it may be assumed that the two specified reasons do not exhaust the list of the most important reasons for an increase of supervision. Due to this situation and to the relatively small number of responses, they will be not analysed any further.

The distribution of responses of people (from groups of respondents defined in accordance with the position they occupy) to the question which of the specified barriers may exist in the case of the person delegating power is presented in Figure 6.

The analysis of the presented data implies that the most common barrier for the person who delegates power to the subordinates indicated by the respondents is the desire to know all the details (33,3\% of all the respondents), the erroneous conviction that „I can do that better" (23,2 \% of all the respondents), no confidence towards the subordinates and reluctance towards promotion of the subordinates (in each case $18,9 \%$ responses of all the respondents); the least common barrier indicated by the respondents is the inability to organise the control of the delegated activities $(6,5 \%$ responses $)$. It must also be noted that approximately $10 \%$ of the respondents stated that they are not able to identify such barriers, and the same percentage of the respondents said they have no specific opinion about the subject. 
The analysis of the distribution of responses of the people (from groups of respondents defined in accordance with the position they occupy) to the question which of the specified barriers may exist in the case of those who delegate power, implies that the highest percentage of managers $(60 \%)$, middlelevel directors (37,5\%) and low-level directors $(33,3 \%)$, as well as line employees indicated that such a barrier is a desire to now all the details. It must also be noted that with equal frequency the low level directors indicated a sense of threat felt by the person delegating power, a lack of acceptance of the possibility of committing an error by the subordinate and a lack of confidence towards the subordinate. The independent specialists most commonly indicated a lack of confidence towards the subordinate $(27,6 \%)$, while the specialists and assistants indicated an erroneous conviction of the superiors that they can do the tasks better (30\% and 33,3\%, respectively).

The analysis of the distribution of responses of the people (from groups of respondents defined in accordance with their education) to the question which of the specified barriers may exist in the case of those who delegate power, implies that the respondents from all the specified groups most commonly perceived the barrier to spring from the desire to now all the details. This value amounted in the case of people with a postgraduate education to $42,8 \%$, in the case of those with an M.A. to $32,6 \%$, in the case of those with an engineering education to $41 \%$, in the case of those with a post-secondary education to $25,4 \%$, in the case of those with a secondary education to $36 \%$, and in the case of those with a vocational education to $25 \%$. It must also be emphasized that the majority of the respondents in virtually all the groups defined in accordance with the form of ownership and size of the company (except for the respondents working in state companies which employ more than 150 employees) perceived the barrier to spring from the desire to now all the details.

The percentage was contained in the range between $21 \%$ and $45 \%$. In the case of the respondents working in state companies which employ more than 150 employees, the majority perceived the barrier to be the erroneous conviction of the superiors that they can do the tasks better $(25 \%)$. Most people whose seniority is shorter than two years and longer than ten years perceived the barrier to be related to be overburdened with work; the people whose seniority is $2-5$ years pointed out to bad organisation of work; and the people whose seniority is longer than two years, but does not exceed five years, indicated the fear of responsibility.

Due to the aforementioned factors as the most important barriers, it must be assumed that the desire to know all the details, the erroneous conviction that "I can do that better", sense of threat, a lack of acceptance of the possibility of an error committed by a subordinate, and a lack of confidence towards the subordinates.

The analysis of the responses given by the respondents implies that the most common barrier indicated by the respondents as regards those who power is delegated to is being overburdened with work $(33,3 \%$ of all the respondents), a lack of experience $(20,2 \%$ of all the respondents), fear of responsibility, independence and an increase of the difficulty of work (18,5\% each), as well as an escape from responsibility and bad organisation of work $(18,1 \%$ each). It must also be noted that approximately $15 \%$ of the respondents stated that they are not able to indicate such barriers, and approximately $10 \%$ of the respondents declared they have no specific opinion on the subject.

The distribution of responses of people (from groups of respondents defined in accordance with the position they occupy) to the question which among the specified barriers may exist in the case of the people power is delegated to, implies that the highest percentage of managers (45\%) indicated the escape from responsibility, the middle-level directors indicated the fear of responsibility and independence, as well as being overburdened with work $(25 \%$ each). The latter was also mentioned by most independent specialists $(41,4 \%)$, specialists $(35 \%)$ and line employees $(18,8 \%)$.

It must also be noted that the identical percentage of line employees perceived the barriers that may exist in the case of the people power is delegated to, apart from being overburdened with work, to relate to a bad organisation of work and excessive subordination to the superiors. In the other groups of respondents most low level directors $(33,3 \%)$ and assistants $(25 \%)$ indicated fear of responsibility and independence. 
[\% responses of the total respondents number]

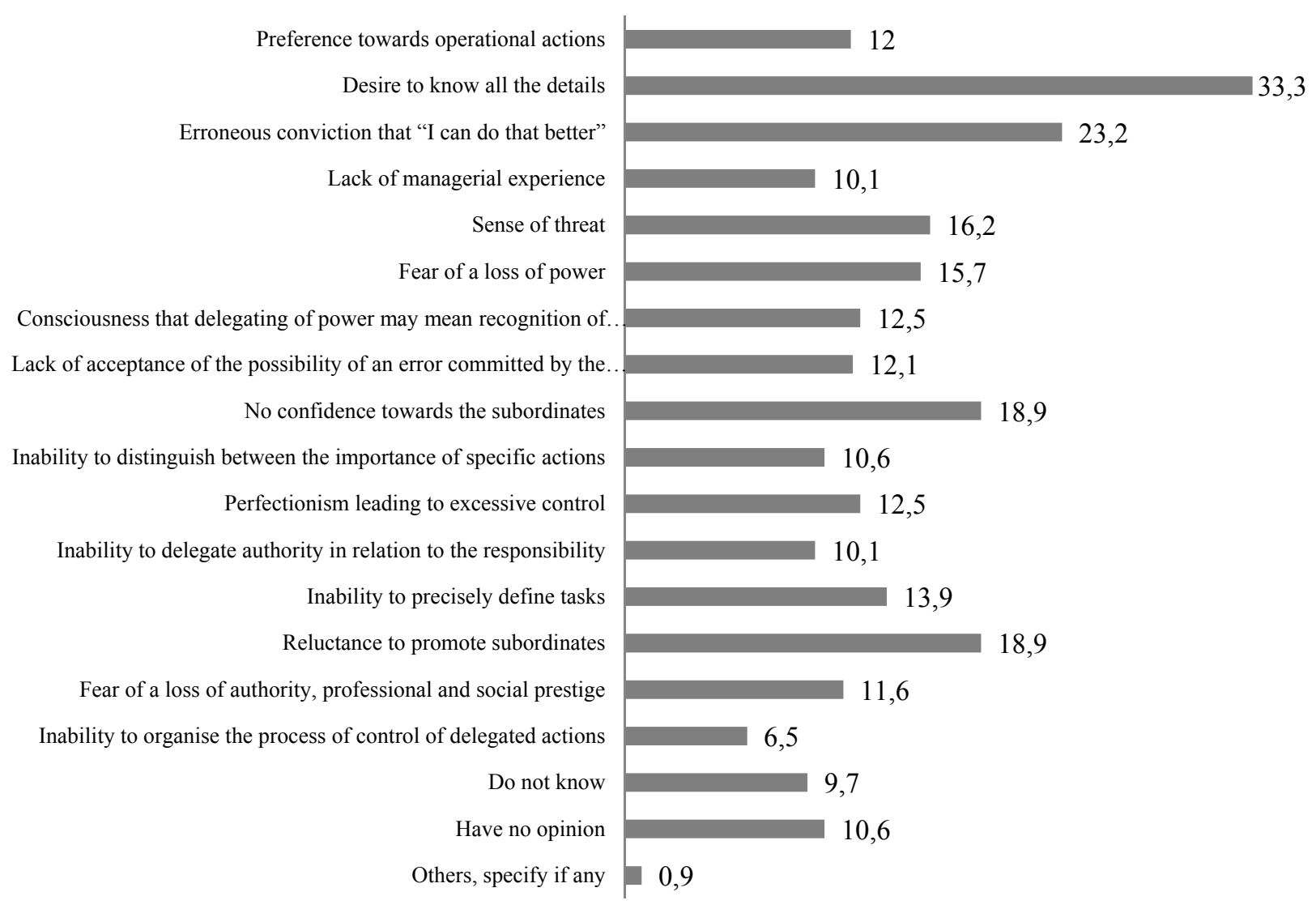

Figure 6. Barriers of those who delegate power

(source: [3])

The distribution of responses of people (from groups of respondents defined in accordance with their education) to the question which among the specified barriers may exist in the case of the people who delegate power implies that most people with a postgraduate education fear of responsibility and independence, as well as fear of changes (50\% each), most people with an M.A. (58,7\%), a post-secondary $(33,3 \%)$ and secondary education (28\%) indicated an escape from responsibility, and most people with an engineering education (33,3\%) indicated a bad organisation of work. Since at the same time the respondents regardless of the form of ownership of their company and its size (identified with the number of employed persons) most commonly perceived the most serious barriers to be bad organisation of work, fear of responsibility and independence, and being overburdened with work, then the most important barriers that might exist in the case of people power is delegated to may be considered to be escape from responsibility, fear of responsibility and independence and being overburdened with work, bad organisation of work and excessive subordination to the superiors.

The distribution of responses of people (from groups of respondents defined in accordance with the position they occupy) to the question which among the specified barriers may exist in the case of the people power is delegated to, implies that the highest percentage of managers (45\%) indicated an escape from responsibility, middle-level directors indicated a fear of responsibility and independence and being overburdened with work (25\% each). The latter was also indicated by most independent specialists $(41,4 \%)$, specialists $(35 \%)$ and line employees $(18,8 \%)$. It must also be pointed out that the identical percentage of line employees perceived the barriers that may exist in the case of the people power is delegated to, to relate also to a bad organisation of work and excessive subordination to the superiors. In the other groups of respondents most low level directors $(33,3 \%)$ and assistants $(25 \%)$ indicated fear of responsibility and independence. 


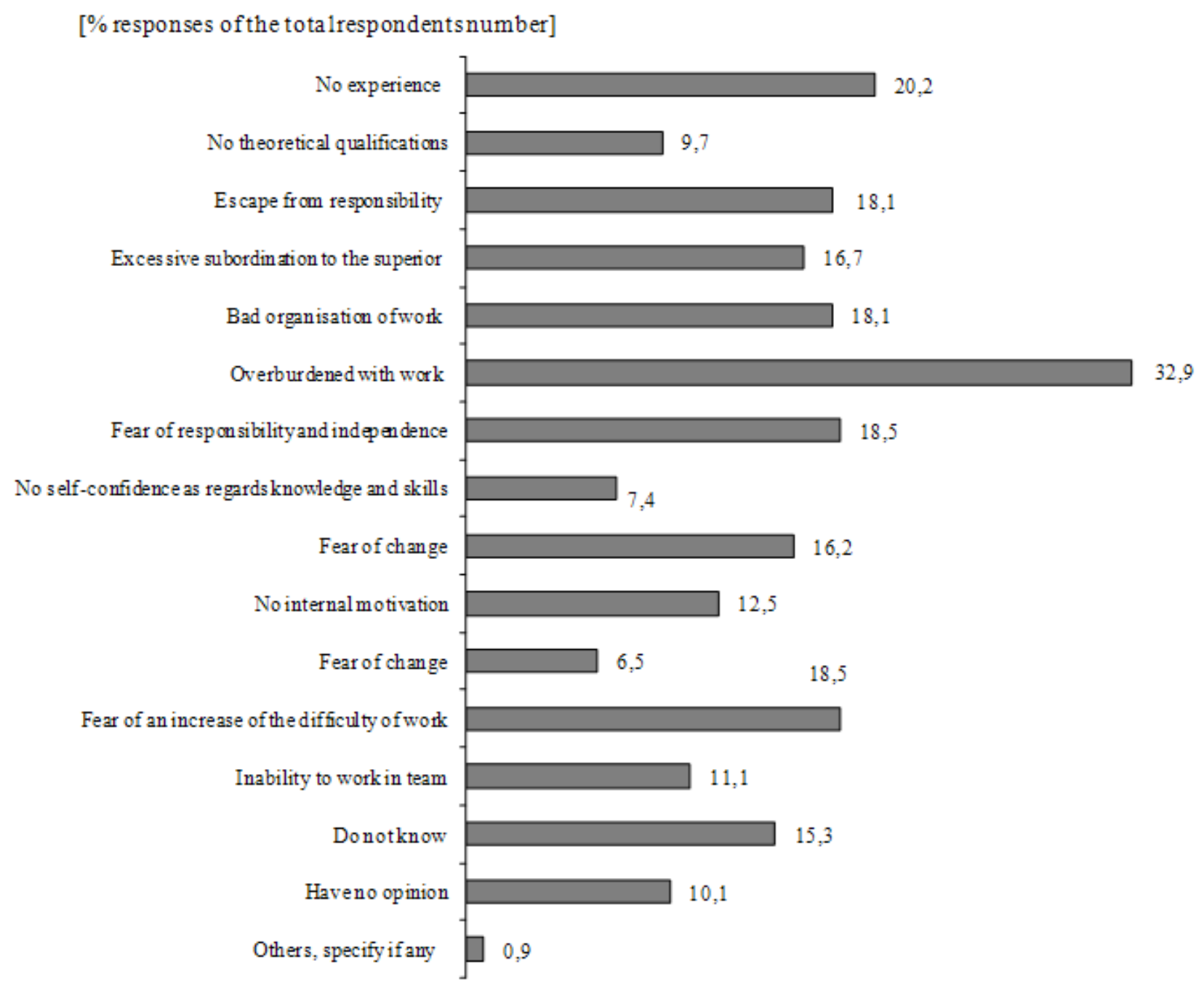

Figure 7. Barriers which exist in case of employees power is delegated to (source: [3])

The distribution of responses of people (from groups of respondents defined in accordance with their education) to the question which among the specified barriers may exist in the case of the people who delegate power implies that most people with a post-graduate education fear of responsibility and independence, as well as fear of changes $(50 \%$ each), most people with an M.A. $(58,7 \%)$, a post-secondary $(33,3 \%)$ and secondary education (28\%) indicated an escape from responsibility, and most people with an engineering education $(33,3 \%)$ indicated a bad organisation of work. Since at the same time the respondents regardless of the form of ownership of their company and its size (identified with the number of employed persons) most commonly perceived the most serious barriers to be bad organisation of work, fear of responsibility and independence and being overburdened with work, the most important barriers that may exist in the case of people power is delegated to include an escape from responsibility, fear of responsibility and independence and being overburdened with work, a bad organisation of work and excessive subordination to the superiors.

An analysis of the data presented in Figure 8 implies that the external barrier which precludes delegation of power, which is most commonly indicated by the respondents is the single-person management tradition (24,5\% of all the respondents), a lack of qualified personnel $(24,1 \%$ of all the respondents) and misunderstandings regarding the scope of power and responsibility $(22,7 \%$ of all the respondents). It must also be noted that approximately $10 \%$ of the respondents stated that they are not able to identify such barriers or have no specific opinion on the subject.

The distribution of responses of people (from groups of respondents defined in accordance with the position they occupy) to the question which among the specified 
external barriers preclude delegation of power implies that the highest percentage of managers $(40 \%)$ and middle-level directors $(33,4 \%)$ indicated the singleperson management tradition. Most low level directors (25\%), independent specialists $(37,9 \%)$ and specialists $(32,5 \%)$ perceive the most important barrier in a lack of qualified personnel, while line employees (25\%) and assistants $(41,7 \%)$ indicate the necessity to make quick decision while there is no time to explain the principles of delegation of power. It must also be pointed out that the low level directors apart the lack of qualified personnel frequently indicated $(25 \%$ people in this group of respondents) a lack of employees willing to participate, while the line employees perceived an additional barrier in the misunderstandings regarding the scope of power and responsibility $(25 \%$ of the people in this group of respondents).

The distribution of responses of people (from groups of respondents defined in accordance with their education) to the question which among the specified external barriers preclude delegation of power implies that most of the people with a post-graduate education $(35,7 \%$ of this group of respondents) perceives the barrier in a vertical and downward flow of information, while the people with an M.A.

$(34,8 \%)$ and an engineering education $(28,2 \%)$ believe the barrier is a lack of qualified personnel. The people with a post-secondary education most commonly indicated $(23,8 \%)$ a lack of financial resources; while the people with a secondary education indicated the tradition of single-person management $(32 \%)$. The people with a vocational education were not able to identify any barriers. It must also be pointed out that the people with an M.A. perceived such a barrier with an equal frequency $(34,5 \%)$ as in the case of a lack of qualified personnel in misunderstandings regarding the scope of power and responsibility.

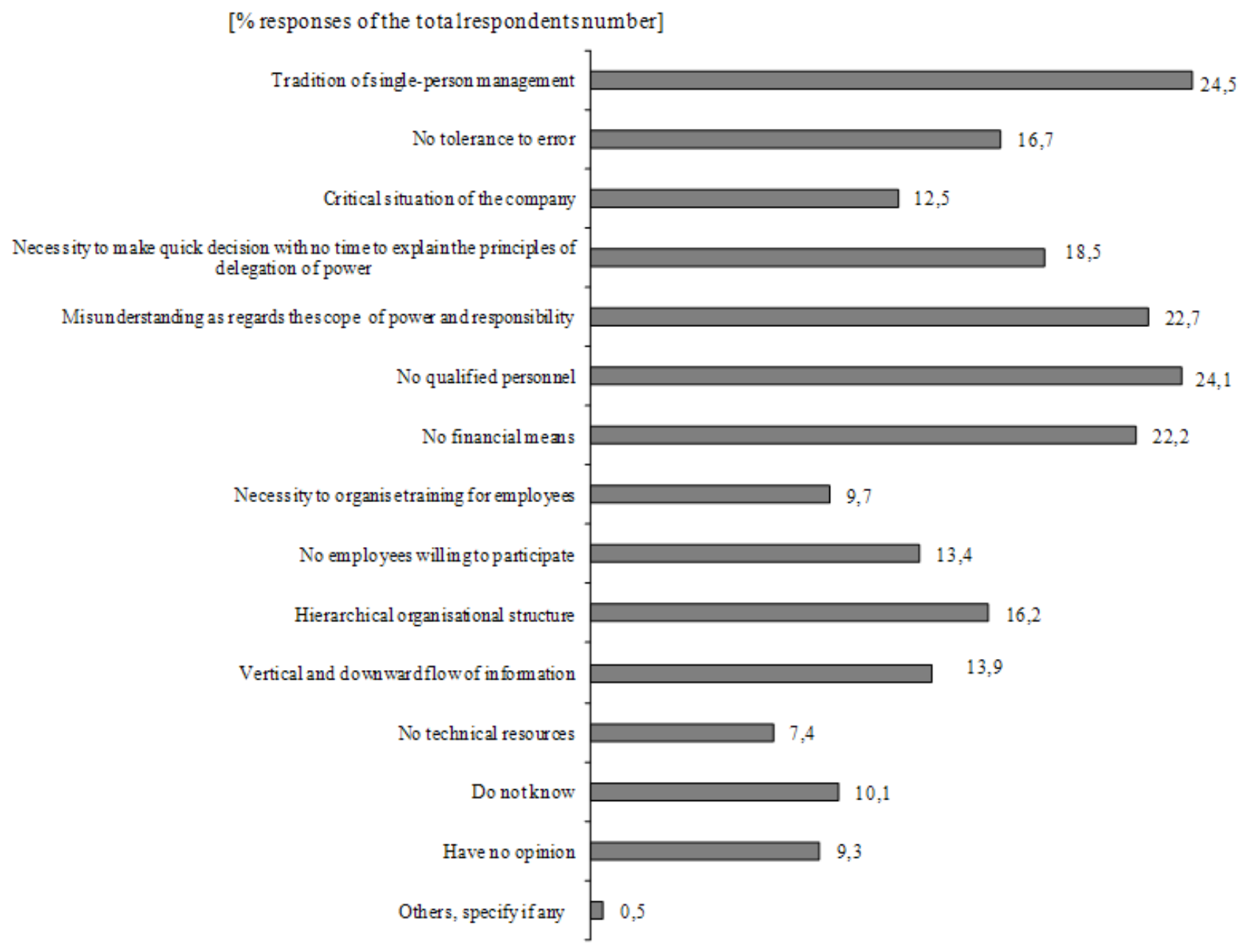

Figure 8 . External barriers precluding delegation of power (source: [3]) 


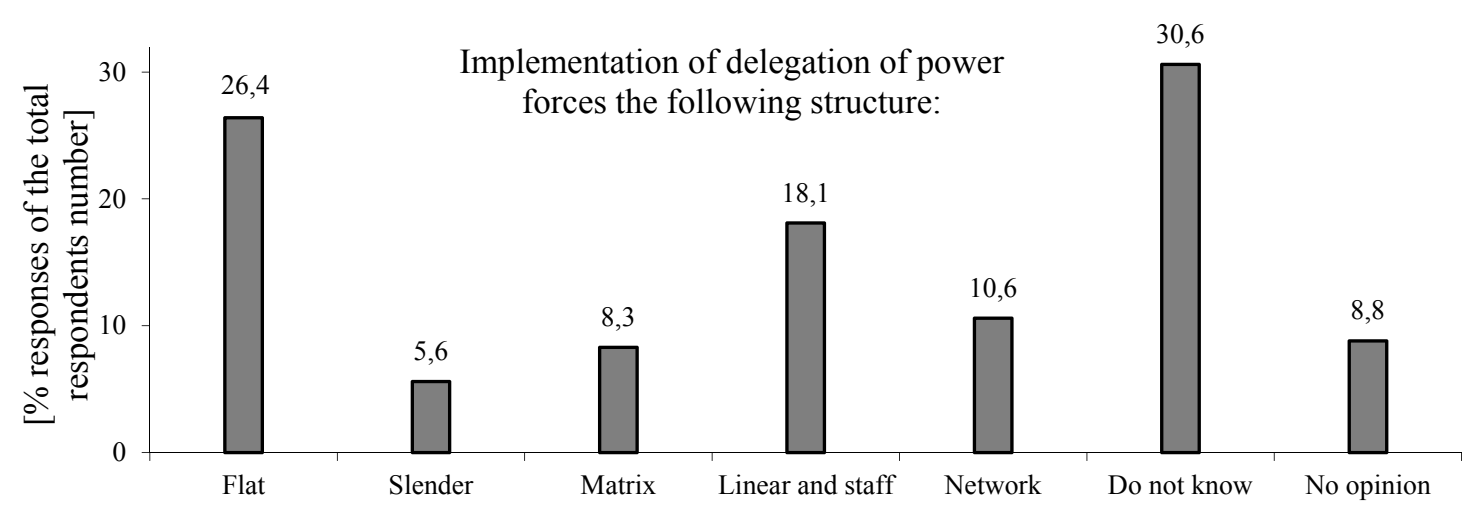

Figure 9. Organisational structure forced by delegation of power (source: [3])

The distribution of responses of people (from groups of respondents defined in accordance with the seniority of the groups of respondents) implies that solely those whose seniority did not exceed two years most frequently perceived the barrier to be the tradition of single-person management, while those whose seniority amounted to more than two years most frequently perceived the barrier to consist in misunderstandings regarding the scope of power and responsibility and a lack of qualified personnel. Considering the distribution of the responses (from groups defined in accordance with the form of ownership of the company and the number of the employees) we come to a conclusion that the respondents employed in state companies most frequently perceived the barriers in a lack of financial resources, the tradition of single-person management, a lack of qualified personnel and a hierarchical organisational structure.

The conclusions which spring from the realised analyses of the distribution of responses given by the respondents imply that among the specified barriers which preclude delegation of power, the most important ones are the tradition of single-person management, misunderstandings regarding the scope of power and responsibility, a lack of qualified personnel and al lack of adequate financial means. Sometimes delegation of power is precluded by a hierarchical organisational structure and a vertical, downward flow of information.

During the following part of the study the respondents were expected to indicate the type of the organisational structure which is forced by delegation of power. The total number of 216 respondents gave 235 responses, while most respondents $(26,4 \%)$ indicated that delegation of power forces a plane structure, and slightly fewer indicated that it forces a linear-staff structure $(18,1 \%)$ and a network structure $(10,6 \%)$. The fewest respondents indicated that delegation of power forces a matrix structure $(8,3 \%)$ and a slender structure $(5,6 \%)$. One of the respondents stated that delegation of power causes another type of organisational structure, but gave no details. It must also be pointed out that $8,8 \%$ of the respondents have no specific opinion, while as many as $30,6 \%$ of the respondents said they did not know what kind of organisational structure is related to the empowerment in their company. The last remark relates first of all to the people with a vocational education, since all the respondents in this group declared they were not able to give any answer to this question.

The distribution of responses of people (from groups of respondents defined in accordance with the position they occupy) implies that the highest percentage of managers $(60 \%)$, independent specialists $(37,9 \%)$ and specialists $(17,5 \%)$ indicated that delegation of power forces a plane organisational structure. It must be pointed out that the same percentage of specialists believe that empowerment forces a linear and staff structure. A similar opinion was expressed by the highest percentage of middle-level directors $(37,5 \%)$ and low-level directors (25\%), assistants (25\%) and line employees $(18,8 \%)$, while the same percentage of people in the last group of respondents believe that delegation of power contributes to formation of a slender organisational structure. A response to this question was most difficult for the people in the group of assistants $(58,3 \%)$, specialists (35\%), line employees $(31,2 \%)$ and independent specialists $(27,6 \%)$.

In relation to the percentage values, it might be concluded that generally the higher the position 
occupied by the respondents, the higher percentage of people stating that delegation of power contributes to forming of a plane organisational structure.

The distribution of responses of people (from groups of respondents defined in accordance with their education) to the question implies that the highest percentage of the respondents of all the specified groups are convinced that delegation of power forces a plane organisational structure. This view was expressed by $21,4 \%$ of the people with a post-graduate education, $36,9 \%$ of the people with an M.A., 30,8\% of the people with an engineering education, $20,6 \%$ of the people with a post-secondary education and $24 \%$ of the people with secondary education. Such views are also shared by most respondents in all the groups defined on the basis of seniority and most of those who work in private companies distinguished on the basis of the number of employees. Only in the case of state companies which employ more than 150 employees, most employees do not share this view and indicate that empowerment forces a linear and staff structure.

It may be concluded that most respondents believe that implementation of empowerment leads to flattening of the organisational structure, although at the same time a significant part of the people indicated that the modifications in management contribute to forming a linear and staff structure. Taking into account the characteristic features of these types of structures, it must be pointed out that delegation of power generally contributes to streamlining of management.

It should also be pointed out that the fundamental advantage of the linear and staff structure is the fact that such a structure combines the advantages of the linear structure and a functional structure, while the disadvantage of such a structure is the possibility of its gradual evolution (,shifting”) towards the functional structure.

\section{[\% responses of the total respondents number]}

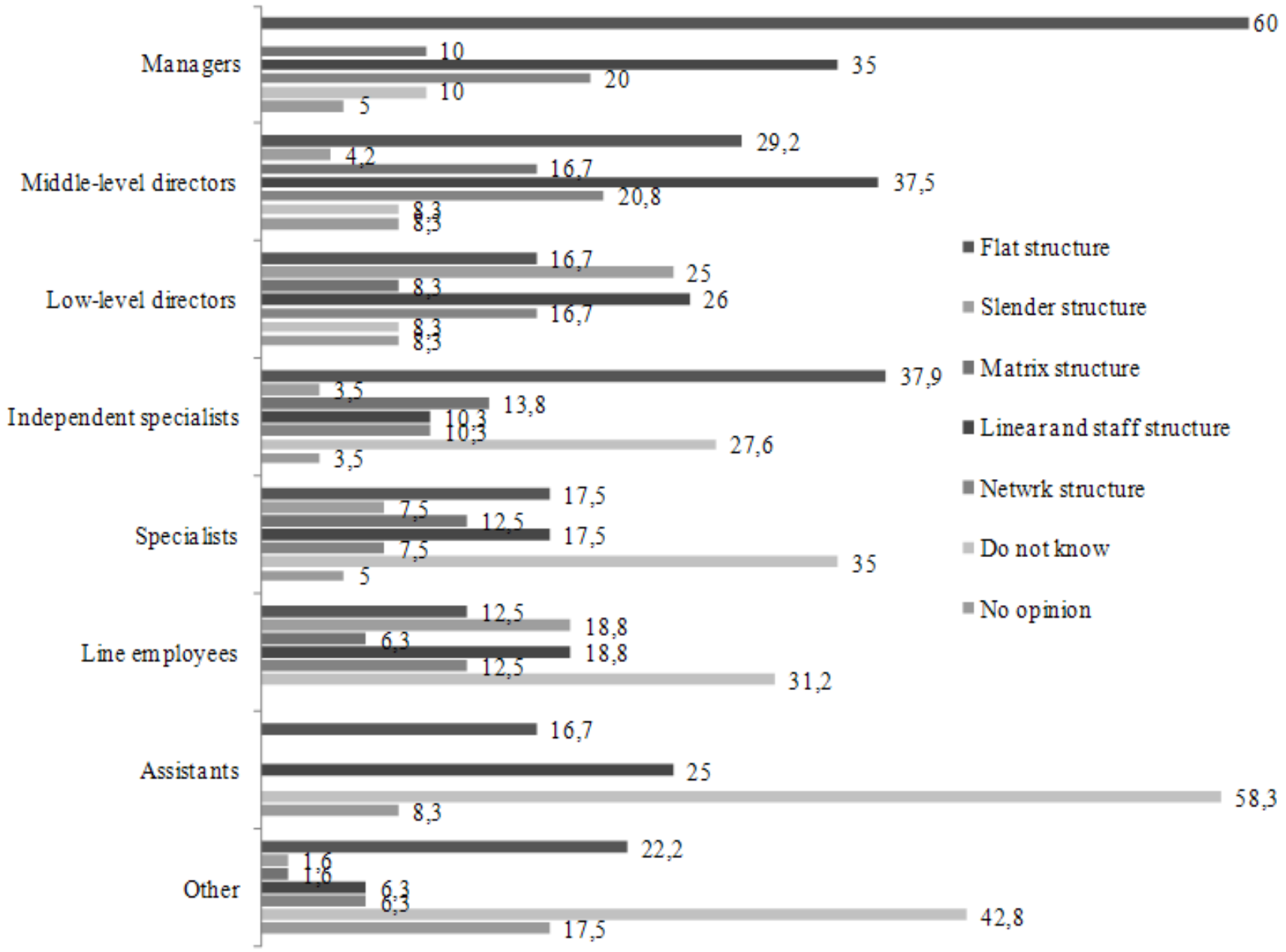

Figure 10. Indications given by the respondents regarding organisational structure forced by delegation of power (source: [3]) 
The effect of such a transformation of the organisational structure may be an excessive development of functional relations between specific levels and their transformation into parallel official relations [1, page 143]. The fundamental advantages of the linear structure are the clear-cut nature and exactitude of the distribution of tasks, authority and responsibility, as well as a full implementation of the principle of unity of management. The basic disadvantages of the structure are a reduction of the role of specialists and the requirement of universalism (versatility) regarding the directors. It must also be emphasized that if in a stable environment and in case of simple technologies the requirement is possible to meet, then in a turbulent environment with complex technologies, there is no practical possibility to fulfil the requirement in question.

\section{$4 \quad$ Summary}

Directors, while performing their duties, must draw inspiration from new tendencies regarding performance of such roles in organisations, which have been successful. It applies both to the forming of the structures of such organisations and management. It is suggested to continuously adapt the organisational structure adequately to the requirements of the environment, and build it up around processes including all the stages, from development of a new product to sales and after-sales service. As far as management is concerned, and taking into account the advantage of the organisation, apart from a collective decision-making process, directors should consider implementation of empowerment and subsidiarity, as well as delegation of a part of their duties and authority to the subordinates. Moreover, they should apply broadly interpreted ethics and skilfully manage the „contracts" between the organisation and its members, while moulding their attitudes, they should base upon the knowledge of the characteristic personality traits and prevent cognitive dissonance.

The analysis of the presented data implies that the major barriers in delegation of power are the following: the superior's desire to know all the details, an erroneous conviction of the management: „I can do that better", a sense of threat and a lack of acceptance of the possibility of an error committed by the subordinate, and a lack of confidence towards the subordinates. The external barrier precluding delegation of power which was most frequently indicated by the respondents was the tradition of single-person management (24,5\% of all the respondents) and a lack of qualified personnel (24,1\% of all the respondents) and misunderstandings regarding the scope of power and responsibility (22,7\% of all the respondents). As far as the employees power is delegated to are concerned, the principal barriers are being overburdened with work (32,9\% of the responses), a lack of experience (20,2\% of the responses), fear of responsibility and independence $(18,5 \%$ of the responses) and an escape from responsibility (18,1\% of the responses). In order to implement empowerment in Polish companies the aforementioned barriers must be overcome.

\section{$5 \quad$ References}

[1] Bielski M. - Podstawy teorii organizacji $i$ zarzqdzania. Wydawnictwo C.H. BECK, Warszawa 2002.

[2] Kanter R.M. - The change masters [in] Classics of Organization Behavior (ed. W.E. Natemeyer, J.S. Gilberg). Interstate, Danvill 1989, pp. 358370.

[3] Kułakowska A., Piątkowski Z., Żebrowski W. Opracowanie przeprowadzonych badań empirycznych. Materiał niepublikowany, WSEiZ, 2009.

[4] Lee M., Koh J. - Is empowerment really a new concept? [in] The International Journal of Human Resource Management, Vol. 12, No. 4, 2001, pp. 684-95.

[5] Marzec I. - Empowerment pracowniczy $w$ dqżeniu do doskonalenia organizacji. Instytut Edukacji Interaktywnej, www.zti.com.pl/instytut/pp/referaty/ ref33_full.html, 2010. 